\title{
Envolvimento comunitário na Estratégia de Saúde da Família: dilemas entre institucionalização e efetiva participação
}

| ${ }^{1}$ José Patrício Bispo Júnior, ${ }^{2}$ Poliana Cardoso Martins |

Resumo: Este artigo analisa o desempenho dos Conselhos Locais de Saúde enquanto instrumentos da participação social no âmbito da Estratégia de Saúde da Família. Trata-se de pesquisa quali-quantitativa com triangulação de métodos. $\mathrm{O}$ campo de estudo foi o município de Vitória da Conquista-BA. Os dados e informações foram obtidos por meio de análise da agenda de compromissos, dos formulários de acompanhamento, das atas das reuniōes dos conselhos e por entrevistas semiestruturadas com informanteschave. Os resultados demonstraram que os conselhos locais de saúde apresentam desempenho limitado, com baixa frequência de realização de reuniōes, agenda de compromissos voltada para o próprio conselho e reuniōes pautadas nas dificuldades de acesso aos serviços de saúde. Os baixos níveis de mobilização social e envolvimento comunitário são o principal entrave para o bom desempenho desses fóruns. São apontados problemas sobre representatividade dos conselheiros, desmotivação em participar de atividades voluntárias e sentimento de despreparo em decorrência das fragilidades da formação e capacitação. Conclui-se que a institucionalização dos conselhos locais não é condição suficiente para promover a participação comunitária. São sugeridas algumas iniciativas com potencial de promover a mobilização social e despertar as comunidades para a importância da participação e do envolvimento coletivo.

> Palavras-chave: participação comunitária; conselhos de saúde; saúde da família; atenção primária à saúde; Sistema Único de Saúde.
1 Doutorando em Saúde Pública pela Escola Nacional de Saúde Pública Sérgio Arouca da Fundação Oswaldo Cruz (ENSP/FIOCRUZ). Professor da Universidade Federal da Bahia Instituto Multidisciplinar em Saúde (IMS-UFBA). Núcleo de Epidemiologia e Saúde Coletiva (NESC). Endereço eletrônico: jpatricio@ufba.br

2 Doutoranda em Saúde Pública pela Universidade Federal de Minas Gerais. Professora da Universidade Federal da Bahia Instituto Multidisciplinar em Saúde (IMS-UFBA). Núcleo de Epidemiologia e Saúde Coletiva (NESC). Endereço eletrônico: policmartins@yahoo.com.br

Recebido em: 16/06/2012. Aprovado em: 28/10/2012. 


\section{Introdução}

Nas últimas décadas, vários países realizaram reformas participativas. As pressões da sociedade civil por maior interferência na esfera estatal multiplicaram os espaços de participação, que, por sua vez, possibilitaram inserir na agenda pública as demandas e aspirações de diversos segmentos sociais. Essas reformas promoveram a abertura de muitos setores de governo e de entidades estatais aos movimentos e representações da sociedade.

A ideia de participação no setor saúde apresenta diferenças ideológicas e conceituais, sendo utilizada por diferentes correntes com o intuito de alcançar objetivos diversos. Um número de tipologias de participação comunitária tem sido desenvolvido com o propósito de explicar as possibilidades e os níveis de participação (MITTON et al., 2010). Draper e seus colaboradores (2010) propõem um modelo de cinco níveis de participação, que formam uma escala crescente: utilização dos serviços, compartilhamento de informações, mobilização, colaboração e empoderamento. Segundo os autores, o nível mais elevado possibilita interferências sobre o processo decisório, com o envolvimento da comunidade no planejamento, avaliação e monitoramento dos serviços.

No Brasil, o Movimento da Reforma Sanitária, embalado pelos ideais de redemocratização e reestruturação do sistema de saúde, apresenta como grande conquista a criação do Sistema Único de Saúde (SUS). Sua organização fundamenta-se nos princípios de universalidade, integralidade, equidade, descentralização, regionalização e participação comunitária. Esta última é um dos requisitos fundamentais para a implantação e consolidação do SUS. Em 1990, são publicadas as leis 8.080/90 e 8.142/90 (BRASIL 1990a, 1990b), que institucionalizam e regulamentam a participação popular e o controle social na gestão do SUS, tendo como instâncias legalmente instituídas as conferências e os conselhos de saúde.

Atualmente, os conselhos congregam milhares de cidadãos que, investidos do papel de representantes de segmentos sociais, discutem com gestores e profissionais os rumos mais adequados para o SUS e para a saúde da coletividade. Desse modo, forma-se uma densa constelação de espaços de participação, interlocução e aprendizado de valores democráticos e de cidadania. Essa miríade de canais participativos é o mais amplo fenômeno de democratização setorial e de compartilhamento de poder do Estado com a sociedade. 
No entanto, os conselhos apresentam problemas e dificuldades diversas, que criam obstáculos ao seu efetivo desempenho. Gerschman (2004), ao refletir sobre a maturidade da democracia brasileira, destaca que as dificuldades para a consolidação da participação no SUS requerem uma discussão específica sobre a relação entre Estado e democracia, o que exige conceituar esta em relação às esferas pública e privada, ao indivíduo e à sociedade, à justiça e à equidade.

Importante destacar que a participação no Brasil está longe de ser homogênea e modifica-se a depender da cultura política local, do grau de mobilização social e da disposição das autoridades em respeitar e valorizar o envolvimento da sociedade na gestão (CÔRTES, 2009). Assim, existem experiências participativas transformadoras em muitas localidades, enquanto em outras há situações de inócua participação e parca mobilização.

De acordo com a Lei 8.142 e a Resolução CNS 333/2003, que dispõem sobre a participação da comunidade na gestão do SUS, os conselhos de saúde devem ser obrigatoriamente criados nas esferas municipal, estadual e federal. Todavia, como instrumento de ampliação dos canais de participação, alguns municípios decidiram pela implementação de Conselhos Locais de Saúde (CLS). Estes, normalmente, atuam na área de abrangência de uma determinada unidade de saúde - por exemplo, uma Unidade de Saúde da Família (USF) - e têm como propósito discutir e definir com a comunidade local os principais problemas de saúde, as formas de intervenção e o envolvimento da comunidade.

A participação comunitária é um dos requisitos da Atenção Primária à Saúde (APS). De acordo com Giovanella e Mendonça (2008), o atributo de orientação para a comunidade - característica essencial da APS - impõe a necessidade do seu envolvimento e participação nas decisões sobre a saúde da coletividade. A concepção de atenção primária da Estratégia de Saúde da Família preconiza equipe de caráter multiprofissional, que trabalhe com definição de território de abrangência e com responsabilização pela população residente na área. Pretendese que equipe e população estabeleçam vínculos e possam identificar em conjunto os principais problemas de saúde e elaborar estratégias para o enfrentamento dos determinantes do processo saúde/doença, para a garantia da assistência integral às famílias (GIOVANELLA E MENDONÇA, 2008).

Nesse sentido, os CLS mostram-se importantes instrumentos para mobilização comunitária e fortalecimento do SUS e do PSF. Essas instâncias possuem 
capacidade de ampliar o envolvimento e a participação da sociedade nas questôes locais e globais de saúde, bem como de compartilhar poder e proporcionar um fecundo debate sobre as questões técnicas e políticas dos problemas comunitários.

Diante desse contexto, o objetivo do presente artigo é analisar o desempenho dos CLS enquanto instrumentos da participação social no âmbito da Estratégia de Saúde da Família.

\section{Metodologia}

Este é um estudo de casos múltiplos com níveis de análise imbricados (YIN, 2010). Utilizou-se de metodologia quanti-qualitativa, com triangulação de métodos. De acordo com as definiçōes de Flick (2009), a triangulação é utilizada para promover a qualidade da pesquisa e possibilitar o aprofundamento do objeto investigado. Ela implica que os pesquisadores assumam diferentes perspectivas sobre uma questão em estudo e empreguem diversos métodos e técnicas a fim de produzir conhecimentos além daqueles possibilitados por uma única abordagem (FLICK, 2009).

O estudo foi desenvolvido em Vitória da Conquista, terceira maior cidade do estado da Bahia, com 308.901 habitantes, localizada na região do semiárido nordestino. Sua economia está baseada na agricultura, na pecuária e na prestação de serviços, com destaque para saúde e educação. Trata-se de um centro de referência nas áreas para uma região de mais de 70 municípios. No que tange à gestão do SUS, a cidade é sede da Macrorregião de Saúde do sudoeste da Bahia. Com relação à Atenção Primaria à Saúde, em 2009, a rede era composta por 35 unidades de saúde: sete Unidades Básicas Tradicionais (UBT) e 28 Unidades de Saúde da Família (USF) (VITÓRIA DA CONQUISTA, 2010).

Segundo os documentos oficiais, o município decidiu priorizar a atenção básica e fortalecer o controle social (VITÓRIA DA CONQUISTA, 2010). Foram criados Conselhos Locais de Saúde em todas as unidades básicas, estruturados seguindo à lógica de um conselho para cada unidade de saúde. Assim, em cada UBT e USF foi criado um único CLS, com representantes dos profissionais de todas as equipes da unidade e usuários pertencentes à área de atuação.

Os dados e informações que subsidiaram a investigação foram coletados por meio de análise documental e entrevistas semiestruturadas com informantes- 
chave. Os documentos analisados foram: agenda de compromisso do CLS, formulários de acompanhamento e atas das reuniōes dos CLS.

O município mantém uma coordenação de controle social na estrutura da Secretaria Municipal de Saúde, com o intuito de assessorar e monitorar o desempenho do Conselho Municipal de Saúde e dos conselhos locais. Essa coordenação, em consonância com a realidade e as necessidades de cada comunidade, firmou uma agenda de compromisso com cada CLS, em que foram estabelecidos objetivos e metas a serem cumpridos pelos conselhos. Nesta pesquisa, foram analisadas as agendas de todos os CLS do município e realizada categorização dos compromissos firmados.

Foi também desenvolvido pela gestão municipal um formulário para o acompanhamento das reuniôes do CLS. Após cada reunião, o presidente do conselho deve preencher o formulário e encaminhá-lo à coordenação do controle social. Ele é composto pelas seguintes informaçōes: data da reunião, relação de participantes, número de participantes da comunidade, assuntos tratados na reunião e deliberações e decisões aprovadas. Diante disso, também foram analisados os formulários e as atas das reuniōes de todos os CLS com o propósito de identificar: a frequência de realização das reuniōes; o quantitativo da participação - especialmente de membros da comunidade; e os principais temas discutidos e deliberados nas reuniōes.

As entrevistas semiestruturadas foram realizadas em seis CLS, buscando-se contemplar os diversos bairros da zona urbana da cidade. Em cada conselho, foram realizadas seis entrevistas entre os conselheiros locais de saúde - três entre os usuários e três entre os profissionais da equipe - contemplando os de nível médio e superior, num total de 36 conselheiros entrevistados. As entrevistas foram realizadas entre março e junho de 2009. Para as agendas de compromisso, formulários de acompanhamento e atas da reunião foram realizadas análises retrospectivas para o período de dois anos anteriores à realização das entrevistas, correspondendo ao período de março de 2007 a fevereiro de 2009.

$\mathrm{Na}$ análise das entrevistas, utilizou-se o processo de codificação e categorização temática proposto por Gibbs (2009). O primeiro momento dessa etapa foi a definição dos códigos, ou seja, a descrição da ideia analítica de cada código realizada de forma sistemática e constante. Em seguida, o texto foi lido de maneira reflexiva para identificação dos códigos. Após a codificação 
1318 foi realizado o processo de categorização axial: o cruzamento dos códigos de um mesmo entrevistado ou de vários sujeitos. Dessa forma, as categorias foram desenvolvidas, refinadas e interconectadas (GIBBS, 2009).

$\mathrm{O}$ projeto que deu a origem à pesquisa foi aprovado conforme o parecer 164/2008 do Comitê de Ética em Pesquisa da Universidade Estadual do Sudoeste da Bahia. Todos os sujeitos, antes de serem entrevistados, foram esclarecidos sobre os objetivos e métodos da pesquisa. Foi realizada a leitura do Termo de Consentimento Livre e Esclarecido (TCLE), assinado em duas vias, ficando uma em posse do investigador e outra do entrevistado.

\section{Resultados}

\section{Frequência das reuniōes}

$\mathrm{Na}$ tabela 1, abaixo, são apresentadas as frequências das reuniões realizadas pelos conselhos locais, conforme as faixas percentuais de reuniōes previstas. Como devem ocorrer reuniōes ordinárias uma vez por mês, são previstas 22 reunióes para o período estudado, descontando-se o período de recesso nos meses de janeiro.

$\mathrm{Na}$ análise dos percentuais, observa-se baixa frequência de realização das reuniões. Dos 28 CLS, apenas quatro realizaram mais do que $75 \%$ das reuniōes previstas para o período. A maior parte dos conselhos, 15 do total, realizou entre $50 \%$ e $74,9 \%$ das reuniōes. Seis CLS realizaram entre $25 \%$ e $49,9 \%$, e em três conselhos foram realizadas menos de $25 \%$ das reuniões que deveriam ocorrer.

Tabela 1. Frequência e percentual das reuniōes do CLS, por faixas de reuniōes previstas para o período. Vitória da Conquista - BA, março/2007 a fevereiro/2009.

Percentuais

Total

\begin{tabular}{lcc} 
& $\mathrm{N}$ & $\%$ \\
\hline Realização de 0 a 25\% de reuniōes previstas & 3 & $10,7 \%$ \\
Realização de 25 a 50\% de reuniões previstas & 6 & $21,4 \%$ \\
Realização de 50 a 75\% de reuniões previstas & 15 & $53,6 \%$ \\
Realização de 75 a 100\% de reuniões previstas & 4 & $14,3 \%$ \\
Total & 28 & $100 \%$ \\
\hline
\end{tabular}




\section{Agenda de compromissos}

Sobre a agenda de compromissos, observa-se na tabela 02 que a maioria dos temas pactuados entre os conselhos e a coordenação de controle social do município refere-se ao estímulo à mobilização social e participação comunitária, com $37,7 \%$, e a questões relativas à organização interna do CLS, com 20,8\%. Esses dois temas juntos correspondem a $58,5 \%$ de todas as ações pactuadas.

Em menor proporção, são também firmados compromissos para o desenvolvimento de açôes de combate às doenças endêmicas (11,3\%), ações de promoção à saúde $(7,5 \%)$ e busca de melhorias para questões estruturais do bairro (7,5\%), dentre outras. Em três dos CLS não foi firmada agenda.

A análise da agenda de compromissos demonstra que o principal objetivo da gestão é despertar nas comunidades o envolvimento comunitário e a participação social no âmbito do PSF. Em quase todos os CLS, a agenda de compromissos aponta objetivos referentes ao fortalecimento e à estruturação do próprio CLS, bem como estratégias e compromissos diversos para atrair a população para participar das reuniōes do conselho.

Tabela 2. Frequências e percentuais das Agendas de Compromisso dos Conselhos Locais de Saúde de Vitória da Conquista (BA), março/2007 a fevereiro/2009.

\begin{tabular}{lcc} 
Principais temas da Agendas de Compromisso & \multicolumn{2}{c}{ Total } \\
\hline Estímulo a mobilização social e participação comunitária & 20 & $\mathbf{~} \%$ \\
Organização interna do CLS & 11 & $20,8 \%$ \\
$\begin{array}{l}\text { Desenvolvimento de ações preventivas de doenças prevalentes } \\
\text { na comunidade }\end{array}$ & 6 & $11,3 \%$ \\
$\begin{array}{l}\text { Ações de promoção e educação em saúde } \\
\text { Mobilização para conquistas de melhorias estruturais no bairro }\end{array}$ & 4 & $7,5 \%$ \\
$\begin{array}{l}\text { Ação de prevenção contra o alcoolismo } \\
\text { Distribuição de brindes a quem participar de quatro reuniões } \\
\text { consecutivas do CLS }\end{array}$ & 2 & $7,5 \%$ \\
Estabelecimento de parcerias com associações de bairros & 2 & $3,8 \%$ \\
Promoção ações relacionadas ao meio ambiente & 2 & $3,8 \%$ \\
Total & 2 & $3,8 \%$ \\
\hline
\end{tabular}




\section{Temas pautados nas reunióes dos CLS}

$\mathrm{Na}$ análise do formulário de acompanhamento e das atas dos CLS, observase que os temas de maior discussão referem-se às dificuldades de acesso aos serviços de saúde. Conforme indicado na tabela 03, as dificuldades de acesso ao atendimento no PSF e nos encaminhamentos para serviços especializados são o principal tema discutido nas reuniōes $(20,4 \%)$. O tema é tratado em todos os CLS, e em muitos deles é assunto recorrente. Os temas relativos às dificuldades de acesso são levados ao conselho a partir de queixas e reclamações dos usuários.

Embora frequentes, esses temas ficam apenas no campo da discussão. De maneira geral, não há deliberações a seu respeito. Evidencia-se que o conselho é utilizado como espaço de queixas e reclamações dos usuários.

A baixa participação da comunidade e as questōes relativas à organização do próprio conselho aparecem como segundo tema mais discutido (18\%). O frágil envolvimento da população estimulou o debate e desencadeou uma série de deliberaçôes voltadas para realização de campanhas e mobilizações no intuito de despertar maior interesse pelas atividades dos CLS.

$\mathrm{O}$ terceiro assunto mais discutido refere-se às ações intersetoriais, com 15,3\% de todos os temas pautados. Os conselhos, em muitos momentos, trataram de assuntos diversos que extrapolavam o setor saúde, por exemplo, violência e transporte público. Sobre esses temas, é prática comum dos conselhos deliberar pelo encaminhamento de documentos e convites às autoridades dos diversos setores públicos e privados para reivindicar e obter esclarecimentos sobre os respectivos problemas.

Outros assuntos, como realização de campanhas sanitárias (14\%), combate às doenças de maior incidência nas comunidades $(9,7 \%)$, questôes estruturais do bairro $(7,5 \%)$, combate ao consumo de álcool e drogas (4,6\%) e programas sociais do governo federal $(3,8 \%)$ são também discutidos pelos conselheiros, com o propósito de promover a melhoria das condiçôes sociais e de saúde das comunidades. 
Temas discutidos das reuniōes dos CLS

Total

\begin{tabular}{lcc}
\hline $\begin{array}{l}\text { Dificuldades de acesso ao atendimento no PSF e serviços } \\
\text { especializados }\end{array}$ & 76 & $20,4 \%$ \\
Baixa participação da comunidade/ Organização do Conselho & 67 & $18,0 \%$ \\
Ações de intersetorialiade & 57 & $15,3 \%$ \\
Campanhas sanitárias e de prevenção & 52 & $14,0 \%$ \\
Discussão sobre principais doenças que afetam a comunidade & 36 & $9,7 \%$ \\
Problemas de infraestrutura da comunidade & 28 & $7,5 \%$ \\
Combate ao consumo de álcool e drogas & 17 & $4,6 \%$ \\
Feiras de saúde & 14 & $3,8 \%$ \\
Discussão sobre programas sociais do governo & 14 & $3,8 \%$ \\
Outros & 11 & $3,0 \%$ \\
Total & 372 & $100 \%$ \\
\hline
\end{tabular}

\section{Percepções dos atores}

O desempenho dos conselhos locais de saúde é percebido pelos entrevistados como ainda incipiente. Existe um consenso nas falas sobre a importância dos CLS para o aprimoramento da assistência à saúde e para melhoria das condições de vida das comunidades; todavia, tanto trabalhadores quanto usuários destacam que os conselhos não exercem suas atribuiçõoes de maneira plena. Também emerge de maneira consensual que os principais fatores de influência para o baixo desempenho dos CLS são a fraca participação e o pouco envolvimento comunitário. Parece prevalecer nas comunidades estudadas um misto de individualismo e imediatismo. As pessoas demonstrariam interesse em se envolver apenas em questôes que lhes trouxessem benefícios pessoais diretos e imediatos.

A população não dá muita importância pro conselho, só quando é interesse próprio. Se não for, não dá. Se você colocar um tema, por exemplo, o Bolsa Família, a gente enche o posto. Se colocar dengue, vêm dez pessoas. Se você colocar combate às drogas, vêm três. (Entrevistado 06) 
Muitos informantes destacam que a participação de alguns usuários nos conselhos locais é motivada por interesses individuais relativos a facilitar o acesso aos serviços de saúde. É destacado que muitas pessoas participam com intuito de se aproximarem e tornarem-se conhecidos dos profissionais da unidade, e, com isso, conseguirem marcar consultas e exames com maior facilidade. Os entrevistados relataram existir dificuldade de acesso para o atendimento nos serviços especializados e no próprio PSF, especialmente em consultas médicas e odontológicas. Com isso, alguns indivíduos projetam a participação nos CLS como caminho para viabilizar as demandas por assistência. Ao perceberem que a participação no conselho não agiliza o agendamento de suas consultas e exames, os usuários afastam-se e desenvolvem sentimentos de frustração e descrédito para com o conselho.

A maioria das pessoas vem para a reunião pensando que vai resolver sobre o exame dela que tá aqui há três meses, que tá aqui há seis meses. (Entrevistado 29)

Tem gente que tá aqui no conselho só pra ser beneficiado com atendimento da médica, com marcação de exames. Se eles não forem atendidos, eles somem, não tão nem aí. Se você falar com eles, eles não querem nem saber. (Entrevistado 07)

O baixo desempenho do CLS é também relacionado pelos entrevistados às questóes de representatividade e à fragilidade das organizações comunitárias. As falas revelam que as escolhas dos conselheiros representantes dos usuários ocorrem, na maioria das vezes, entre aqueles que mais frequentam a unidade de saúde. Esse processo é apontado como gerador de distorçôes dos interesses defendidos nas reuniōes. Em decorrência da ausência de espaços de discussão coletiva e da inexistência ou debilidade de organizações comunitárias, os representantes mantêm frágeis vínculos com os diversos segmentos e grupos que compõem a comunidade. Não raro, omitem-se ou mantêm posturas no conselho não correspondentes com os interesses e necessidades da população representada.

Por outro lado, os entrevistados também apontam que o desinteresse das comunidades e a ausência de instituições de representação coletiva geram um processo de isolamento e ausência de apoio aos representantes. As falas evidenciam não existir discussão entre representantes e representados sobre os temas tratados nas reuniōes. Diante do desinteresse das comunidades, a responsabilidade pelo bom desempenho do conselho e do próprio PSF é atribuída exclusivamente ao representante. 
A comunidade elegeu a pessoa ali, ela quer que a pessoa faça tudo. Aí quando eles

chegam no posto pra ser atendido e tiver um monte de dificuldade, eles falam que foi culpa daquela pessoa que elegeram. Vai cobrar daquela pessoa, é isso que eles pensam. (Entrevistado 11)

A questão do voluntariado na atividade de conselheiro de saúde é também apontada pelos entrevistados como motivo do desinteresse de boa parte das pessoas. Diante disso, um grupo dos entrevistados revela que uma parcela importante da população não se sente estimulada em participar por não receber pagamento pela função desenvolvida. Muitos destacam que as atribuições de um conselheiro de saúde são trabalhosas e demandam tempo e dedicação, sendo poucos os que se dispõem a abrir mão dos seus afazeres pessoais para desempenhálas voluntariamente em benefício do interesse coletivo.

A maioria das pessoas não gosta de ser voluntário em nada, muito menos no conselho. Porque acha que tudo tem que ser pago, que uma informação que sai da boca tem que ser pago. (Entrevistado 13)

Houve também convergência de opiniōes sobre a importância das capacitações e treinamentos para um bom desempenho dos conselhos. Os entrevistados revelaram que um grupo de conselheiros já participou de cursos oferecidos pela Secretaria Municipal de Saúde, ao passo que outros não realizaram qualquer treinamento ou formação para o exercício da função. Isso é apontado como um fator limitante e que compromete as atividades e desempenho dos CLS.

\section{Discussão}

Os conselhos locais estudados apresentam, de maneira geral, pouca efetividade na realização das reuniōes, embora os resultados mostrem que o nível de organização e funcionamento dos CLS não é uniforme. Alguns conselhos possuem organização incipiente e dificuldades de reunir-se ordinariamente, enquanto outros mantêm uma frequência mediana na realização das reuniões. Em todos os conselhos, em diversas ocasiōes, não houve reunião por falta de quórum, especialmente por ausência das representações dos usuários.

A dificuldade para manter frequência regular nas reuniōes dos conselhos é uma característica comum em muitas localidades, sobretudo em contextos locais e conselhos municipais de cidades de pequeno porte. Em estudo avaliativo da atenção primária em 21 municípios nordestinos, verificou-se ser pouco frequente 
a realização de reuniōes dos CLS (ROCHA et al., 2008). No interior de Minas Gerais, pesquisa realizada em município de pequeno porte constatou que, para um período de 19 meses, ocorreram apenas sete reunióes do Conselho Municipal de Saúde (COTTA et al., 2011). Realidade semelhante foi também observada em conselhos de áreas rurais do Nordeste do Brasil, com número de reuniões realizadas inferior a $50 \%$ do previsto para o período observado (BISPO JÚNIOR; SAMPAIO, 2008). Em todos os casos, a irregularidade na realização das reuniōes guarda relação próxima com os níveis incipientes de envolvimento comunitário também observados em Vitória da Conquista.

Sobre os temas abordados nas reuniōes, observa-se que o principal assunto é a dificuldade de acesso aos serviços assistenciais. Importante destacar as recorrentes discussões relacionadas às limitações de acesso aos próprios serviços prestados pelo PSF. Os problemas de agendamento para consultas na atenção primária e também nos níveis secundários e terciários são observados em várias localidades do país. Em Campinas, no estado de São Paulo, foram observadas dificuldades de agendamento tanto para os profissionais do PSF como para especialistas e serviços de referência (ONOCKO-CAMPOS et al., 2012). Serapioni e Silva (2011) apontam que a qualidade dos serviços é aspecto crítico da Estratégia de Saúde da Família, e destacam como principais entraves: número de famílias por equipe muito superior ao preconizado; grande quantidade de equipes que atuam sem a presença do profissional médico; e elevada rotatividade de profissionais de nível superior.

Onocko-Campos e seus colaboradores (2012) identificaram que, muitas vezes, usuários do PSF apresentam uma compreensão excessiva e uma espécie de autoculpabilização pelas falhas do serviço, mesmo diante das dificuldades de acesso e da desassistência crônica. Comportamentos dessa natureza podem ser indicativos da não assimilação dos direitos sociais ou ainda de processos que naturalizam o desrespeito a esses direitos. Ambos os fatores contribuem para a apatia e o diminuto envolvimento comunitário nos conselhos de saúde.

No município estudado, o conteúdo da agenda de compromisso, a análise das atas e as próprias falas dos conselheiros demonstram que o principal entrave para o pleno desempenho dos conselhos locais é o baixo nível de interesse e de participação da população. Nesse sentido, evidencia-se que a institucionalização de um espaço 
participativo, mesmo com apoio e incentivo da gestão municipal, não é condição suficiente para promover a mobilização social e o envolvimento comunitário.

Sobre essa questão, Soratto e seus colaboradores (2010), em estudo sobre a participação no âmbito da ESF, também concluíram que a criação de espaços institucionalizados não garante a participação e o controle social no contexto do SUS. Para os autores, nas relações entre profissionais de saúde, gestores e população, as informações repassadas e os assuntos discutidos são de caráter eminentemente técnico e normatizador, o que gera grande desinteresse da população.

Longhi e Canton (2011), por sua vez, alertam que o significado político crucial da participação tem sido redefinido e reduzido aos aspectos da gestão. Assim, a simples participação nos espaços institucionais conduz a população apenas ao cumprimento do papel de aprovadores de projetos e pacotes ministeriais, seja para o estabelecimento de rotinas ou para aquisição de financiamentos.

Alguns fatores são apresentados pelos entrevistados como desencadeantes do baixo nível de interesse e de envolvimento comunitário, dentre eles, o desinteresse na defesa do bem coletivo e a busca de benefícios individuais e imediatos. Esses fatores situam-se em sentido antagônico aos propósitos dos conselhos de saúde, que, na maioria das vezes, propiciam benefícios de caráter coletivo e em longo prazo.

Duas questôes podem ajudar a explicar a conformação desse predomínio por interesses privados e imediatos. Primeiramente, a sociedade brasileira ainda apresenta fortes traços de uma cultura patrimonialista e clientelista, se esses valores estão presentes no seio da sociedade, também o estão entre os usuários do PSF e os participantes dos conselhos de saúde (ESCOREL; MOREIRA, 2009). Em segundo lugar, há ampla disseminação dos valores da sociedade de consumo, em que a busca da satisfação pessoal e da conquista de bens materiais assume supremacia diante dos princípios da solidariedade e de valores coletivos.

Participar das reuniōes do conselho com o intuito de apenas facilitar o acesso aos serviços de saúde demonstra a existência de incompreensões sobre suas finalidades e também das debilidades do SUS e do PSF em garantir uma assistência digna à população. Os mecanismos de participação no SUS, embora com mais de duas décadas de institucionalização, ainda não são totalmente conhecidos e compreendidos pela população. Diversos estudos demonstram 
desconhecimentos e distorções no sentido do que venham a ser os propósitos dos conselhos de saúde. Martins e colaboradores (2011), em uma pesquisa com usuários do PSF, identificaram que pouco mais de 5\% tinha conhecimento da existência dos conselhos de saúde. O desconhecimento da população sobre os canais participativos no SUS compromete o desempenho dos conselhos pela limitação da participação a poucos cidadãos e, consequentemente, pela frágil capacidade de articulação com outros segmentos populares e sociais (MARTINS et al., 2008).

Sobre o caráter voluntário dos conselhos, o desinteresse justificado pela ausência de remuneração também revela os traços da cultura de desvalorização do bem coletivo, e pode ser um indicativo da descrença na capacidade do Estado em prover digna proteção social. As dificuldades para a garantia dos direitos de cidadania e a crise de credibilidade do Estado brasileiro em decorrência da corrupção, do desvio de verbas e da descrença nos políticos (LONGHI; CANTON, 2011) contribuem para que os indivíduos vislumbrem adquirir algum benefício pecuniário em seu envolvimento com as instâncias estatais. Além do mais, a autocomparação com os profissionais e gestores participantes dos conselhos, remunerados por suas atividades profissionais, pode desencadear entre os usuários a impressão de que estão sendo explorados por não receberem por sua participação.

No que se refere à representatividade, trata-se de um problema comum aos conselhos em várias esferas de gestão. No caso especifico dos conselhos locais, ele é potencializado pela ausência ou fragilidade das organizações de representação comunitária. A escolha de conselheiros entre os usuários mais presentes na unidade de saúde e sem o envolvimento dos diversos segmentos da comunidade pode conduzir a distorções na representação dos interesses.

Para Pitkin (1978), a representação caracteriza-se pelo "agir no lugar de”, visão complementada por Lavalle e seus colaboradores (2006), que sugerem como representação o fato de tornar presente alguém ou algum interesse mediante a figura de algum intermediário. Dentre as dimensōes do processo representativo, a questão da legitimidade apresenta-se como característica de maior relevância para efetivação da representação. Para Santos e Avritzer (2005), a legitimidade da representação envolve pelo menos três dimensões: a da autorização, a da identidade e a da prestação de contas. Nesse sentido, a representação nos 
conselhos locais de saúde padece com a falta de legitimidade, visto que, em muitos casos, os representantes não são autorizados pelas comunidades, não se identificam com os interesses dos diferentes grupos e não prestam contas das atividades desenvolvidas, nem das posturas assumidas.

Outro fator destacado como limitador do desempenho dos CLS foi o sentimento de despreparo dos conselheiros. A coordenação municipal de controle social, em articulação com o então polo de educação permanente, ofertou um curso destinado aos conselheiros locais de saúde. Mesmo com o curso, os conselheiros expressaram limitações relativas aos conhecimentos e competências necessárias para o bom desempenho do papel de conselheiro. Situações dessa natureza possibilitam a reflexão sobre a baixa efetividade dos cursos esporádicos e das capacitações pontuais.

A formação de conselheiros de saúde deve ser pautada nos princípios da educação permanente, em que formação e mobilização aconteçam de maneira articulada e interdependente e sejam construídas numa perspectiva de produção coletiva de saúde (BRASIL, 2007). A educação permanente deve ter a capacidade de promover o empoderamento dos atores locais, desencadeando um processo de reflexão e transformação contínua das práticas pessoais e institucionais. Segundo Cotta e colaboradores (2011), a educação e a formação de conselheiros não podem estar pautadas apenas no repasse de informações sobre as leis que regem o SUS e dos conteúdos necessários para o exercício da atribuição. Devem, sobretudo, despertar a consciência de que a participação popular é um processo destinado ao desenvolvimento de uma nova cultura política democrática capaz de transformar os níveis de saúde e os modos de vida das populações.

Fedozzi (2009) aponta que um dos principais limitantes da participação é a criação dos conselhos de saúde a partir de vontades exógenas ou heterônomas à dinâmica real dos atores locais. Essa situação, caracterizada como participação concedida (DEMO, 2001), expressa a criação dos conselhos por entes governamentais em que se atribui à Sociedade Civil, muitas vezes de maneira arbitrária, a responsabilidade da representação do conselho. Em muitos casos, essas comunidades não têm tradição de organização e militância no campo da saúde e não dispõem de pessoas interessadas em desempenhar tal representação, situação propícia a uma baixa participação de atores sociais e à frustração da comunidade pelo fraco desempenho dos conselhos. 
Importante destacar também que a criação de fóruns de participação potencializa as expectativas da população sobre o desempenho dos serviços. A mobilização de pessoas e o debate sobre as condições de vida e saúde, como proposto pelos conselhos locais, levam naturalmente ao aumento da demanda dos serviços. Nesse sentido, conforme destaca Avritzer (2007), aos governos cabe desempenhar uma administração efetiva no atendimento das carências demandadas. O não atendimento das necessidades identificadas nos espaços participativos pode converter-se em um catalisador do descrédito, da frustração e do abandono. Assim, a criação e, sobretudo, a manutenção de entidades participativas estão condicionadas à capacidade do Estado de proporcionar respostas adequadas às deliberações das entidades, bem como de organizar as demandas emergentes.

\section{Considerações finais}

O estudo demonstrou que os conselhos locais de saúde apresentam desempenho limitado, com baixa frequência na realização das reuniōes - pautadas nas dificuldades de acesso aos serviços de saúde - e agenda de compromissos voltada ao próprio conselho. As percepções dos conselheiros revelam que os baixos níveis de participação social e o frágil desempenho dos CLS estão associados às limitações do acesso aos serviços e ao envolvimento dos conselheiros apenas em busca de benefícios pessoais, sobretudo para agilizar a realização de consultas e exames. Também são apontados problemas sobre a representatividade dos conselheiros, desmotivação na participação por se tratar de uma atividade voluntária e sentimento de despreparo em decorrência das fragilidades de formação e capacitação.

Embora se tenha evidenciado que a institucionalização da participação, por meio de conselhos locais de saúde, não é condição suficiente para promover a mobilização social e o envolvimento comunitário, não se pode perder de vista que esses fóruns podem ser espaços de promoção da cidadania e aprimoramento das condiçôes de vida e saúde das populações. Apesar dos obstáculos vivenciados no cotidiano dos conselhos, estes se apresentam como importantes instrumentos para o alargamento da democracia e consolidação do SUS.

Nesse sentido, são sugeridas algumas iniciativas com potencial de promover a mobilização social e despertar as comunidades para a importância da participação 
e do envolvimento coletivo. Existe a necessidade de maior sensibilidade e responsividade dos gestores em saúde em atender as necessidades sociais emanadas do conselho. O interesse e a participação são potencializados diante da percepção de que os conselhos atuam verdadeiramente como espaços de escuta e diálogo e de que os gestores se empenham em incorporar as demandas identificadas. Também os cursos e capacitaçóes esporádicas devem ser suprimidos para o desenvolvimento em âmbito municipal de uma política de educação permanente destinada aos profissionais e conselheiros de saúde, com potencial de reflexão e transformação da realidade vivenciada. É somente a partir da formação de uma consciência crítica e cidadã é que a população irá abdicar do desânimo e da inércia participativa. ${ }^{1}$

\section{Referências}

AVRITZER, L. A participação social no Nordeste. Belo Horizonte: EdUFMG, 2007.

BISPO JÚNIOR, J. P.; SAMPAIO, J. J. C. Participação social em saúde em áreas rurais do Nordeste do Brasil. Revista Panamericana de Salud Pública, Washington DC, v. 23, n. 6, p. 403-9, 2008.

BRASIL. Lei n. ${ }^{\circ}$ 8.080, de19 de setembro de 1990. Dispõe sobre as condições para a promoçãao, proteção e recuperação da saúde, a organização e o funcionamento dos serviços correspondentes e dá outras providências. Diário Oficial da União. Brasília, 19 set 1990.

BRASIL. Lei $n^{\circ}$. 8142, de 28 de dezembro de 1990. Dispõe sobre a participação da comunidade na gestão do SUS e sobre as transferências intergovernamentais de recursos financeiros na área da saúde e dá outras providências. Diário Oficial da Uniāo. Brasília, 28 dez 1990.

Ministério da Saúde. Portaria GM/MS 1996, de 20 de agosto de 2007. Dispōe sobre as diretrizes para a implementação da Política Nacional de Educação Permanente e dá outras providências. Diário Oficial da Uniāo. Brasília, 21 ago 2007.

COTTA, R. M. M. et al. O controle social em cena: refletindo sobre a participação popular no contexto dos Conselhos de Saúde. Physis. Rio de Janeiro, v. 21, n. 3, p. 1121-1138, 2011.

CÔRTES, S. M. V. Conselhos e conferências de saúde: papel institucional e mudança nas relaçōes entre Estado e sociedade. In: FLEURY, S.; LOBATO, L. V. C. (Org.). Participação, democracia e saúde. Rio de Janeiro: Cebes, 2009. p.102-28.

DEMO, P. Participação é conquista. São Paulo: Cortez, 2001.

DRAPER, A. K.; HEWITT, G.; RIFKIN, S. Chasing the dragon: Developing indicators for the assessment of community participation in health programmes. Social Science \& Medicine, v. 71, n. 6, p. 1102-1109, Sept 2010. 
ESCOREL, S.; MOREIRA, M. R. Desafios da participação social em saúde na nova agenda da reforma sanitária: democracia deliberativa e efetividad. In: FLEURY, S.; LOBATO, L. V. C. (Org). Participação, democracia e saúde. Rio de Janeiro: Cebes, 2009. p.229-47.

FEDOZZI, L. J. Democracia participativa, lutas por igualdade e iniqüidades da participação. In: FLEURY, S. e LOBATO, L. V. C. (Org). Participação, democracia e saúde. Rio de Janeiro: Cebes, 2009. p.204-28.

FLICK, U. Qualidade na Pesquisa Qualitativa. Porto Alegre: Artmed, 2009.

GERSCHMAN, S. A democracia inconclusa. 2 Ed. Rio de Janeiro: Fiocruz, 2004.

GIBBS, G. Análise de Dados Qualitativos. Porto Alegre: Artmed, 2009.

GIOVANELLA, L.; MEDONÇA, M. H. M. Atenção Primária à Saúde. In: GIOVANELLA, L. et al. (Org.). Políticas e Sistemas de Saúde no Brasil. Rio de Janeiro: Fiocruz; Cebes, 2008. p. $575-625$.

LAVAlle, A. G.; HOUTZAGER, P. P.; CASTEllO, G. Democracia, pluralização da representação e sociedade civil. Lua Nova: revista de cultura e política. São Paulo, v. 67, p. 49-103, 2006.

LONGHI, J. C.; CANTON, G. A. M. Reflexôes sobre cidadania e os entraves para a participação popular no SUS. Physis: revista de saúde coletiva, Rio de Janeiro, v. 21, n. 1, p. 15-30, 2011.

MITTON,C. et al. Public partipation in health care priority setting: a scopping review. Health Policy, v. 91, p. 219-28, 2009.

MARTINS, P. C. et al. Conselhos de saúde e a participação social no Brasil: matizes da utopia. Physis: revista de saúde coletiva, Rio de Janeiro, v. 18, n. 1, p. 105-121, 2008.

. De quem é o SUS? Sobre as representações sociais dos usuários do Programa Saúde da Família. Ciência \& Saúde Coletiva, Rio de Janeiro v. 16, n. 3, p. 1933-1942, 2011.

ONOCKO-CAMPOS, R. T. et al. Avaliação de estratégias inovadoras na organização da Atenção Primária à Saúde. Revista de Saúde Pública, São Paulo, v. 46, n. 1, p. 43-50, 2012. PITKIN, H. F. The Concept of Representation. Los Angeles: University of California, 1978. ROCHA, P. D. M. et al. Avaliação do Programa Saúde da Família em municípios do Nordeste brasileiro: velhos e novos desafios. Cadernos de Saúde Pública, Rio de Janeiro, v. 24, supl 1. s69-s78, 2008.

SANTOS, B. S.; AVRITZER, L. Introdução: para ampliar o cânone democrático. In: SANTOS, B. S. (org). Democratizar a democracia: os caminhos da democracia participativa. 3 Ed. Rio de Janeiro: Civilização Brasileira, 2005. p.39-82. 
SERAPIONI, M.; SILVA, M. G. C. D. Avaliação da qualidade do programa Saúde da

Família em municípios do Ceará: uma abordagem multidimensional. Ciência \& Saúde Coletiva, Rio de Janeiro, v. 16, n. 11, p. 4315-26, 2011.

SORATTO, J.; WITT, R. R.; FARIA, E. M. Participação popular e controle social em saúde: desafios da Estratégia Saúde da Família. Physis: Revista de Saúde Coletiva, Rio de Janeiro, v. 20, n. 4, p. 1227-1243, 2010.

VITÓRIA DA CONQUISTA. Secretaria Municipal de Saúde. Relatório de Gestão 2009. Vitória da Conquista: Secretaria Municipal de Saúde, 2010.

YIN, R. K. Estudo de Caso: planejamento e métodos. 4 Ed. Porto Alegre: Bookman, 2010.

\section{Nota}

${ }^{1}$ Os autores participaram igualmente de todas as etapas de elaboração do artigo. 


\section{Community engagement in Family Health} Strategy: dilemmas between institutionalization and effective participation

This paper analyzes the performance of Local Health Councils as tools for social participation in the Family Health Strategy. It is a quali-quantitative research with triangulation method. The research took place in the city of Vitoria da Conquista, state of Bahia, Brazil. Data and information were gathered through the analysis of the agenda, followup forms, minutes of meetings of the council and semistructured interviews with key informants. The results show that the local health councils have limited performance, with a low frequency of meetings, commitments directed to the council itself and meetings on difficulties to access health care services. Low levels of social mobilization and community engagement are the main draw-backs for the good performance of these forums. Some problems stand out: counselors' representativeness, lack of motivation to perform voluntary tasks and feeling unprepared due to a poor graduation and training program. We conclude that institutionalization of local councils is not enough to promote community participation. It requires actions that can promote social mobilization and inform communities of the importance of group participation and engagement.

> Key words: community participation; health councils; family health; primary health care; Brazilian Unified Health System. 